\title{
Cumulative incidence and predictors of acquired aortic stenosis in a large population of men followed for up to 43 years
}

Silvana Kontogeorgos ${ }^{1,2^{*}}$ (D), Erik Thunström ${ }^{1,2}$, Georgios Lappas ${ }^{1,2}$, Annika Rosengren ${ }^{1,2}$ and Michael Fu ${ }^{1,2}$

\begin{abstract}
Background: Acquired aortic stenosis (AS) increases with age and has high mortality without intervention. Factors predicting its development are unclear, although atherosclerotic factors are assumed to be involved. Our aim in this study is to estimate the lifetime cumulative incidence and predictors of AS in middle-aged men.

Methods: We included a random sample of men $(n=9998)$ born 1915-1925 in Gothenburg, Sweden. From them, 7,494 were examined and followed until a diagnosis of AS or death (maximum follow-up time 42.8 years). We identified AS diagnosis from the Swedish National Patient Registry and deaths from the Swedish Cause of Death Registry by using International Classification of Disease (ICD) diagnostic criteria. To study time-dependent relationships between AS and risk factors with death as the competing risk, we divided the cohort into three overlapping follow-up groups: 25-43, 30-43 and 35-43 years. We used age-adjusted Cox proportional hazards model to identify predictors of AS.
\end{abstract}

Results: The lifelong cumulative incidence of AS was 3.2\%. At baseline, participants in the third group had a healthier lifestyle, lower body mass index (BMI), blood pressure, and serum cholesterol levels. Higher BMI, obesity, cholesterol, hypertension, atrial fibrillation, smoking and heredity for stroke were associated with AS. With BMI of 20-22.5 as a reference, hazard ratios of being diagnosed with AS for men with a baseline BMl of $25-27.5 \mathrm{~kg} / \mathrm{m}^{2}, 27.5-30 \mathrm{~kg} / \mathrm{m}^{2}$ and $>30 \mathrm{~kg} / \mathrm{m}^{2}$ were 1.99 (95\% Cl 1.12-3.55), 2.98 (95\% Cl 1.65-5.40) and 3.55 (95\% Cl 1.84-6.87), respectively.

Conclusions: The lifetime cumulative incidence of AS in middle-aged male population was 3.2\%. Multiple atherosclerotic risk factors, particularly high BMI might be associated with a higher risk of developing AS.

Keywords: Aortic stenosis, Obesity, Cumulative incidence, Predictive factors

\section{Background}

The incidence of acquired nonrheumatic aortic stenosis (AS) increases dramatically with age [1] and, if left untreated, is associated with high mortality in symptomatic patients [2]. With rising life expectancy, AS is becoming more common and one of the most frequently occurring valvular heart disease. The pathophysiological changes leading to aortic valve sclerosis and AS

\footnotetext{
*Correspondence: silvana.kontogeorgos@vgregion.se

${ }^{1}$ Department of Molecular and Clinical Medicine, Institute of Medicine, Sahlgrenska Academy, University of Gothenburg, Gothenburg, Sweden Full list of author information is available at the end of the article
}

result from the synergy of the mechanical forces and the changes in the tissular environment sharing similarities with changes encountered in ischemic heart disease [3]. Studies have shown an association between AS and obesity $[4,5]$, hypercholesterolemia [6-9] or hypertension $[6,7,10,11]$, with increasing evidence that atherosclerotic risk factors might also affect the development of aortic valve sclerosis and its progression to AS. However, another question arises as to whether the relationships mentioned above between AS and risk factors persist over the life course, considering that several of these factors are prone to change over time. This issue is 
of particular interest given that AS is a slowly progressive disease, generally taking decades to develop. Accordingly, we have recently shown that high body mass index (BMI) in middle aged men may predict AS after 21 years [12]. However, the sample size in that study was small. Here, we aim to determine the cumulative incidence of AS and its associated factors over a lifetime and examine the relationship between BMI and AS in a larger sample size, incorporating a more extended follow-up period.

In the past decades the prevalence of overweight and obesity has been steadily increasing, now emerging as a major health problem [13], obesity being a risk factor for a variety of diseases (e.g., diabetes, cancer, sleep apnoea) and for cardiovascular diseases in general [14]. Moreover, obesity associates with hypertension, left ventricular hypertrophy, abnormal left ventricular geometry [15], and ischemic heart disease [16, 17].

The aims of this study are to investigate the cumulative incidence of AS in a large population and to identify the factors at baseline that could be associated with the AS diagnosis.

\section{Study population and data collection}

This study included participant men in the intervention group of the multifactor Primary Prevention Study (PPS), which began in 1970 in Gothenburg, Sweden [18]. All men $(n=30,000)$ born between 1915 and 1925 (except those born 1923 who were included in another study) and residing in Gothenburg were randomized into three groups: an intervention group of 9998 men and two control groups of similar size. The study had three examination periods: 1970-1973 (baseline), 1974-1977 and 1980-1983. At baseline (1970-1973), the men in the intervention group, then aged 47-55 years, were screened for cardiovascular risk factors (family history of myocardial infarction or stroke, psychological stress, smoking, total cholesterol levels, blood pressure, physical activity, diabetes, overweight) and those with high risk were treated (high blood pressure, severe hypercholesterolemia, heavy smoking). No significant differences in risk factors or outcome (cardiovascular diseases, cancer, and all-cause mortality) were detected in the first 12 years of follow-up, after which the intervention ended [19]. Accordingly, we considered that the final group of individuals, although being a part of an intervention study, represented Gothenburg's general male population.

Information about risk factors (family history, smoking, physical activity during leisure time, diabetes, self-reported weight at age 20) was obtained by questionnaire. Weight was measured in kilograms to the nearest $0.10 \mathrm{~kg}$ and height was measured in meters to the nearest $0.01 \mathrm{~m}$. BMI was calculated as weight in kilograms divided by the square of height in meters. Obesity was defined as $\mathrm{BMI} \geq 30 \mathrm{~kg} / \mathrm{m}^{2}$. Blood pressure (BP) was measured to the nearest $2 \mathrm{~mm} \mathrm{Hg}$ in the sitting position after 5 min of rest. Hypertension was defined as the use of antihypertensive medicines or systolic BP $(\mathrm{SBP})>160 \mathrm{~mm} \mathrm{Hg}$, or diastolic $\mathrm{BP}(\mathrm{DBP})>95 \mathrm{~mm} \mathrm{Hg}$. Pulse pressure (PP) was defined as SBP minus DBP. Total serum cholesterol levels were measured after fasting for $\geq 2 \mathrm{~h}$ and were determined according to standard laboratory procedures. Smoking habits were divided into three categories: current smoker, non-smoker and former smoker ( $>1$ month). Physical activity during leisure time was categorized into a sedentary lifestyle and an active lifestyle (at least $4 \mathrm{~h}$ per week of physical activity). Diagnoses at screening and follow-up (hypertension, diabetes, ischemic heart disease, stroke, atrial fibrillation, heart failure, renal failure) were identified through the Swedish National Patient Registry (NPR). The diagnoses were time-updated for the period 1970-2012.

\section{Follow-up}

All the participants were followed from their baseline examination until October 2012, a registered diagnosis of AS, or death, whichever came first. The maximum follow-up time was 42.8 years (mean 26.8 years).

\section{Data on aortic stenosis}

We used the NPR to identify men with a registered diagnosis of AS and the Swedish Cause of Death Registry to identify those who died and from what causes, based on the personal identification number assigned to each Swedish resident. Loss due to emigration was negligible. AS was defined as a diagnosis of aortic valve disease according to the International Classification of Disease (ICD) diagnostic criteria: code 424.10 for ICD-8 (used until 1986), code 424B for ICD-9 (in use 1987-1996) or code I35.0, I35.2 for ICD-10. Individual patient records for men diagnosed before 1997 were revised manually (the same code was used to classify aortic stenosis and insufficiency in ICD-8 and ICD-9). Patients diagnosed with isolated aortic insufficiency were identified and not included in the AS group.

\section{Statistical analysis}

Continuous variables are expressed as mean \pm standard deviation or median and IQR, as appropriate. Categorical variables are presented as frequencies and percentages. Cumulative incidences of AS were estimated and presented in diagrams for some baseline factors accounting for death as competing risk.

To study the time-dependent relationship between risk of AS and baseline factors and control in some degree the effect of the baseline factors on the competing risk of death, the follow-up period was divided into three 
overlapping time intervals: follow-up between 25 and 43 years, 30 and 43 years and the third group, including the individuals who survived longest, with follow-up between 35 and 43 years.

The associations between the risk of AS and each one of the actual baseline factors and time-updated comorbidities were estimated with the help of a hazard ratio calculated with Cox proportional hazards regression model, where age and the relevant factor were covariates. Although the continuous baseline factors when entered in the Cox model as cubic splines result in a better, albeit marginally, fit (due to possible nonlinear relationship between the factors and the risk of AS), we choose to present the mean (linear) effect of the actual factor over the range of its values and for the actual follow-up period as a summary measurement of the effect on AS risk. While we did not adjust for risk factors that are caused by overweight/obesity such as diabetes, hypertension and dyslipidaemia, we added a second model where we adjusted for sedentary behaviour, baseline smoking and family history.

The statistical analyses were performed using $S A S$ software version 9.2 (SAS Institute Inc, Cary, North Carolina) and $R$ 3.6.2 [20].

\section{Results}

\section{Cumulative incidence of AS}

As shown in Fig. 1, the participation rate was 75\% (7494 individuals). They were followed from the inclusion date until death or October 2012. The mean follow-up time was 27 years and the maximum follow-up was 43 years. The mean age of the participants at baseline was 51 years. Overall cumulative incidence of AS was 3.2\% (242/7494 individuals) over the follow-up period. The corresponding rates in the three subgroups were 3.3\% (149/4491), $2.9 \%(94 / 3297)$ and $2.1 \%(42 / 2019)$ for follow-ups between 25 and 43 years, 30 and 43 years and 35 and 43 years, respectively.

\section{Baseline characteristics}

Baseline and follow-up characteristics of the participants are described in Table 1. Individuals in the group surviving $\geq 35$ years were characterized by the comparatively lower weight and BMI at screening and lower weight gain from age 20. They were also healthier at baseline, with lower BP, PP, and total cholesterol values. They also had a healthier lifestyle with a lower current smokers' rate and fewer living a sedentary lifestyle. In addition, these participants had a more favourable heredity profile, with a lower percentage of stroke or myocardial infarction in parents and siblings. Table 1 presents comorbidities both at baseline (in the group followed up from 0 to 43 years) and time-updated. The comorbidities with the highest

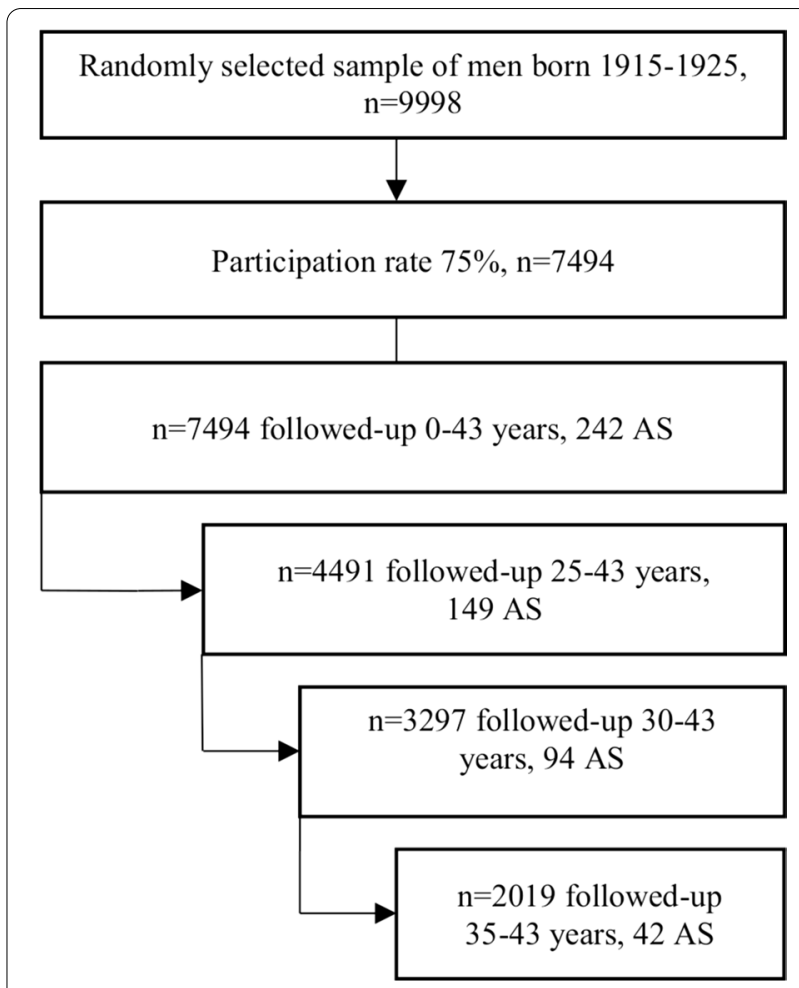

Fig. 1 Flow chart of the study population

prevalence were found in the individuals with the longest follow-up (35-43 years).

\section{Association of AS with baseline factors}

In age-adjusted analyses (Table 2) baseline body weight (per $\mathrm{kg}$ ) at screening was significantly associated with the development of AS in the whole cohort $(\mathrm{HR}=1.02 ; 95 \%$ CI 1.01-1.03 per kg) and in the group followed from 25 to 43 years $(\mathrm{HR}=1.02$; $95 \% \mathrm{CI} 1.01-1.04$ per $\mathrm{kg})$. BMI as a continuous variable was associated with AS in all groups, except the group followed from 30 to 43 years, with the highest HR of 1.12 (95\% CI 1.01-1.24) per BMI unit in the group with the longest survival. Obesity was also associated with AS: the baseline $\mathrm{HR}=1.64(95 \% \mathrm{CI}$ $1.08-2.51$ ), increasing to 1.83 (95\% CI 1.07-3.12) in the group followed up 25-43 years and to 3.13 (95\% CI 1.317.45 ) in men surviving 35 years. There was also an association between serum cholesterol and AS in the whole cohort, HR $=1.26$ (95\% CI $1.15-1.39)$ per $\mathrm{mmol} / \mathrm{L}$. For participants followed 25-43 years, the HR was 1.29 (95\% CI 1.15-1.46) and 1.22 (95\% CI 1.04-1.43) for those followed 30-43 years. There was no association between serum cholesterol and AS in those surviving the longest.

Having a sibling with stroke was also associated with the risk of developing AS during follow-up, retaining its predictive power over all groups, but with relatively 
Table 1 Baseline levels and prevalence of risk factors of the study population at four overlapping periods shrinking towards the end of follow-up

\begin{tabular}{|c|c|c|c|c|}
\hline Follow-up interval & $0-43$ years & $25-43$ years & $30-43$ years & $35-43$ years \\
\hline Number of patients, $n$ & 7494 & 4491 & 3297 & 2019 \\
\hline Aorta events n (\%) & $242(3.2 \%)^{1}$ & $149(3.3 \%)^{1}$ & $94(2.9 \%)^{1}$ & $42(2.1 \%)^{1}$ \\
\hline \multicolumn{5}{|l|}{ Follow up (years) } \\
\hline Mean (SD) & $26.86(10.50)^{1}$ & $9.09(5.08)^{1}$ & $6.46(3.63)^{1}$ & $3.97(2.00)^{1}$ \\
\hline \multicolumn{5}{|l|}{ Baseline levels and factors at screening 1970-1973 } \\
\hline \multicolumn{5}{|l|}{ Age (years) } \\
\hline Mean (SD) & $51.07(2.28)^{1}$ & $50.80(2.30)^{1}$ & $50.56(2.30)^{1}$ & $50.25(2.28)^{1}$ \\
\hline \multicolumn{5}{|l|}{ Weight (kg) } \\
\hline Mean (SD) & $78.85(11.37)^{3}$ & $78.66(10.62)^{2}$ & $78.60(10.44)^{1}$ & $78.50(10.26)^{1}$ \\
\hline \multicolumn{5}{|l|}{ Weight gain, $30(\mathrm{~kg})$} \\
\hline Mean (SD) & $9.84(9.47)^{3}$ & $9.52(8.79)^{2}$ & $9.30(8.53)^{1}$ & $9.05(8.19)^{1}$ \\
\hline Missing & 467 & 245 & 162 & 87 \\
\hline \multicolumn{5}{|l|}{$\mathrm{BMI}\left(\mathrm{kg} / \mathrm{m}^{2}\right)$} \\
\hline Mean (SD) & $25.54(3.27)^{3}$ & $25.42(3.01)^{2}$ & $25.37(2.95)^{1}$ & $25.28(2.85)^{1}$ \\
\hline Obesity (BMI $\geq 30$ kg/m²), n (\%) & $617(8.2 \%)^{3}$ & $296(6.6 \%)^{2}$ & $203(6.2 \%)^{1}$ & $113(5.6 \%)^{1}$ \\
\hline \multicolumn{5}{|l|}{ Systolic blood pressure, $\mathrm{mmHg}$} \\
\hline Mean (SD) & $148.77(21.94)$ & $146.37(21.08)$ & $145.18(20.50)$ & $143.75(20.08)$ \\
\hline Missing & 12 & 4 & 2 & 1 \\
\hline \multicolumn{5}{|l|}{ Diastolic blood pressure, $\mathrm{mmHg}$} \\
\hline Mean (SD) & $94.64(12.94)$ & $93.40(12.43)$ & $92.76(12.30)$ & $92.08(12.01)$ \\
\hline Missing & 13 & 5 & 2 & 1 \\
\hline \multicolumn{5}{|l|}{ Heart rate, beats/min } \\
\hline Mean (SD) & $73.21(13.53)$ & $71.99(12.86)$ & $71.41(12.59)$ & $70.96(12.86)$ \\
\hline Missing & 40 & 19 & 8 & 4 \\
\hline \multicolumn{5}{|l|}{ Pulse pressure, $\mathrm{mmHg}$} \\
\hline Mean (SD) & $54.14(14.82)$ & $52.96(14.30)$ & $52.41(13.96)$ & $51.67(13.82)$ \\
\hline Missing & 14 & 5 & 2 & 1 \\
\hline \multicolumn{5}{|l|}{ Cholesterol, $\mathrm{mmol} / \mathrm{L}$} \\
\hline Median (IQR) & $6.32(1.46)$ & $6.32(1.33)$ & $6.32(1.46)$ & $6.21(1.46)$ \\
\hline Missing & 78 & 29 & 15 & 9 \\
\hline \multicolumn{5}{|l|}{ Smoking, n (\%) } \\
\hline Never & $2201(29.4 \%)^{1}$ & $1546(34.4 \%)^{1}$ & $1222(37.1 \%)^{1}$ & $837(41.5 \%)^{1}$ \\
\hline Current & $3768(50.3 \%)^{1}$ & $1923(42.8 \%)^{1}$ & $1302(39.5 \%)^{1}$ & $674(33.4 \%)^{1}$ \\
\hline Former & $1524(20.3 \%)^{1}$ & $1021(22.7 \%)^{1}$ & $772(23.4 \%)^{1}$ & $507(25.1 \%)^{1}$ \\
\hline Sedentary life, n (\%) & $1919(25.6)^{1}$ & $1002(22.3)^{1}$ & $701(21.3)^{1}$ & $399(19.8)^{1}$ \\
\hline Family history of myocardial infarction, parents ${ }^{1} \mathrm{n}(\%)$ & $1505(20.1 \%)^{1}$ & $859(19.1 \%)^{1}$ & $618(18.7 \%)^{1}$ & $378(18.7 \%)^{1}$ \\
\hline Family history of stroke, parents ${ }^{1} \mathrm{n}(\%)$ & $440(5.9 \%)^{1}$ & $216(4.8 \%)^{1}$ & $141(4.3 \%)^{1}$ & $71(3.5 \%)^{1}$ \\
\hline Family history of myocardial infarction, siblings ${ }^{1} \mathrm{n}(\%)$ & $1989(26.5)$ & $1152(25.7)$ & $815(24.7)$ & $473(23.4)$ \\
\hline Family history of stroke, siblings ${ }^{1} \mathrm{n}(\%)$ & 196(2.6) & $96(2.1)$ & $67(2.0)$ & $38(1.9)$ \\
\hline \multicolumn{5}{|l|}{ Time-updated diagnoses 1970-2012 } \\
\hline Hypertension n (\%) & $3690(49.2 \%)^{1}$ & $2098(46.7 \%)^{1}$ & $1576(47.8 \%)^{1}$ & $1030(51.0 \%)^{1}$ \\
\hline Diabetes n (\%) & $149(2.0 \%)^{1}$ & $285(6.3 \%)^{1}$ & $270(8.2 \%)^{1}$ & $200(9.9 \%)^{1}$ \\
\hline Ischemic heart disease n (\%) & $1131(15.1 \%)^{1}$ & $1232(27.4 \%)^{1}$ & $1014(30.8 \%)^{1}$ & $681(33.7 \%)^{1}$ \\
\hline Stroke n (\%) & $43(0.6 \%)^{1}$ & $318(7.1 \%)^{\mathbf{1}}$ & $362(11.0 \%)^{1}$ & $262(13.0 \%)^{1}$ \\
\hline Atrial fibrillation n (\%) & $4(0.1 \%)^{1}$ & $376(8.4 \%)^{1}$ & $481(14.6 \%)^{1}$ & $391(19.4 \%)^{1}$ \\
\hline Renal failure n (\%) & $1(0.0 \%)^{1}$ & $427(9.5 \%)^{1}$ & $524(15.9 \%)^{1}$ & $419(20.8 \%)^{1}$ \\
\hline Heart failure n (\%) & $0(0.0 \%)^{1}$ & $302(6.7 \%)^{1}$ & $375(11.4 \%)^{1}$ & $291(14.4 \%)^{1}$ \\
\hline
\end{tabular}

$S D$ standard deviation, IQR interquartile range, $B M I$ body mass index

Missing data: ${ }^{1} n=1,{ }^{2} n=2,{ }^{3} n=3$ 
Table 2 Age-adjusted Cox regression hazard model

\begin{tabular}{|c|c|c|c|c|}
\hline Follow-up interval & $0-43$ years & $25-43$ years & 30-43 years & $35-43$ years \\
\hline \multicolumn{5}{|l|}{ Screening age-adjusted HR (95\% CI) } \\
\hline BMI (per BMI unit) & $1.08(1.04-1.12)$ & $1.09(1.03-1.15)$ & $1.07(1.00-1.15)$ & $1.12(1.01-1.24)$ \\
\hline Weight at screening (per kg) & $1.02(1.01-1.03)$ & $1.02(1.01-1.04)$ & $1.02(1.00-1.04)$ & $1.03(1.00-1.06)$ \\
\hline Weight gain, 30 years (per kg) & $1.02(1.01-1.03)$ & $1.02(1.00-1.04)$ & $1.01(0.99-1.04)$ & $1.03(0.99-1.07)$ \\
\hline Obesity (yes/no) & $1.64(1.08-2.51)$ & $1.83(1.07-3.12)$ & $1.62(0.78-3.35)$ & $3.13(1.31-7.45)$ \\
\hline \multicolumn{5}{|l|}{ Smoking } \\
\hline $\begin{array}{l}\text { Former vs never, } \\
\text { Current vs never }\end{array}$ & $\begin{array}{l}1.09(0.76-1.54) 1.32 \\
(0.99-1.77)\end{array}$ & $\begin{array}{l}1.35(0.88-2.08) \\
1.54(1.05-2.25)\end{array}$ & $\begin{array}{l}1.22(0.69-2.14) 1.89 \\
(1.18-3.03)\end{array}$ & $\begin{array}{l}0.70(0.27-1.82) \\
2.08(1.07-4.07)\end{array}$ \\
\hline Sedentary lifestyle (yes/no) & $0.84(0.61-1.16)$ & $0.77(0.50-1.18)$ & $0.81(0.47-1.38)$ & $1.10(0.53-2.30)$ \\
\hline Systolic blood pressure (per mm Hg) & $1.01(1.00-1.01)$ & $1.01(1.00-1.02)$ & $1.01(1.00-1.02)$ & $1.00(0.99-1.02)$ \\
\hline Diastolic blood pressure (per mm Hg) & $1.01(1.00-1.02)$ & $1.01(1.00-1.03)$ & $1.01(0.99-1.02)$ & $1.01(0.98-1.03)$ \\
\hline Pulse pressure (per mm Hg) & $1.01(1.01-1.02)$ & $1.01(1.00-1.02)$ & $1.02(1.00-1.03)$ & $1.00(0.98-1.02)$ \\
\hline Heart rate (beats/min) & $1.01(1.00-1.02)$ & $1.01(1.00-1.02)$ & $1.01(0.99-1.02)$ & $1.00(0.97-1.02)$ \\
\hline Family history of myocardial infarction, parents (yes/no) & $1.33(0.99-1.79)$ & $1.00(0.66-1.50)$ & $0.89(0.52-1.52)$ & $1.03(0.48-2.23)$ \\
\hline Family history of stroke, parents (yes/no) & $1.14(0.86-1.51)$ & $1.23(0.86-1.76)$ & $1.38(0.89-2.15)$ & $1.88(1.00-3.53)$ \\
\hline Family history of myocardial infarction, siblings (yes/no) & $2.06(1.33-3.20)$ & $2.59(1.52-4.42)$ & $1.43(0.58-3.52)$ & $0.00(0.00-\operatorname{lnf})$ \\
\hline Family history of stroke, siblings (yes/no) & $2.02(1.07-3.80)$ & $2.86(1.40-5.84)$ & $3.61(1.58-8.27)$ & $4.35(1.34-14.09)$ \\
\hline Cholesterol (per mmol/L) & $1.26(1.15-1.39)$ & $1.29(1.15-1.46)$ & $1.22(1.04-1.43)$ & $1.07(0.82-1.40)$ \\
\hline Atrial fibrillation (yes/no) & - & $2.00(1.19-3.37)$ & $2.25(1.37-3.69)$ & $2.30(1.19-4.44)$ \\
\hline Diabetes (yes/no) & $1.57(0.50-4.90)$ & $1.19(0.56-2.54)$ & $1.06(0.46-2.44)$ & $1.11(0.40-3.12)$ \\
\hline Hypertension (yes/no) & $1.40(1.09-1.80)$ & $1.57(1.14-2.17)$ & $1.86(1.23-2.82)$ & $1.77(0.95-3.31)$ \\
\hline Ischemic heart disease (yes/no) & $1.54(1.09-2.18)$ & $1.47(1.03-2.08)$ & $1.61(1.06-2.45)$ & $1.49(0.80-2.75)$ \\
\hline Stroke (yes/no) & $1.49(0.21-10.63)$ & $0.60(0.22-1.62)$ & $0.80(0.35-1.83)$ & $1.66(0.74-3.75)$ \\
\hline Heart failure (yes/no) & - & $1.20(0.53-2.74)$ & $1.81(0.96-3.42)$ & $2.69(1.32-5.48)$ \\
\hline Renal failure (yes/no) & - & 8.83 (2.79-27.92) & $1.33(0.18-9.55)$ & 0.00 (0.00-Inf) \\
\hline
\end{tabular}

$B M I$ body mass index, $C l$ confidence interval, $H R$ hazard ratio

wide confidence intervals. The highest HR was observed in the third group (i.e. with the longest survival time), $\mathrm{HR}=4.35$ (95\% CI 1.34-14.09). An association was found in comparing current smokers with never smokers in all but the group followed from 0 to 43 years, with the highest HR of 2.08 (95\% CI 1.07-4.07) in the group with the longest survival time. Hypertension or ischemic heart disease during follow-up were associated with AS in the whole cohort, as well as in the first and middle groups, but not in the group with the longest survival time. Participants with atrial fibrillation had a higher risk of being diagnosed with AS during the follow-up time. The risk increased with more prolonged survival, with the highest $\mathrm{HRs}$ in those surviving $\geq 35$ years $(\mathrm{HR}=2.30 ; 95 \% \mathrm{CI}$ 1.19-4.44). Renal failure was also associated with AS, but only in the individuals followed-up 25-43 years. However, the wide confidence intervals reflects a low statistical precision in this case. The cumulative incidence of AS according to the factors significantly associated with the AS diagnosis is depicted in Fig. 2.

Figure 3 shows the age-adjusted association between baseline BMI and AS, with a continuous increase from low levels up to about $30 \mathrm{~kg} / \mathrm{m}^{2}$; at higher BMI levels, confidence intervals were wide. Using a BMI between 20 and $22.5 \mathrm{~kg} / \mathrm{m}^{2}$ as the reference category, overweight men with a BMI from 25 to $27.5 \mathrm{~kg} / \mathrm{m}^{2}$ from the whole cohort had a 1.99 higher risk of developing AS (95\% CI $1.12-3.55, \mathrm{p}=0.019)$. The risk was $2.98(95 \% \mathrm{CI}$ $1.65-5.40 \mathrm{p}<0.001)$ in the category $27.5-30 \mathrm{~kg} / \mathrm{m}^{2}$ and 3.55 in obese men $\left(\mathrm{BMI} \geq 30 \mathrm{~kg} / \mathrm{m}^{2}\right)(95 \%$ CI $1.84-6.87$, $\mathrm{p}<0.001$ ) (Table 3), after adjusting for age. Results were essentially unchanged after further adjustment for sedentary behaviour, baseline smoking and family history.

\section{Discussion}

In this large population of middle-aged men followed up to 43 years, $242 / 7494$ men (or $3.2 \%$ ) were diagnosed with AS. Multiple factors that heighten the risk of atherosclerosis were also linked to an increased risk of developing AS.

Few studies have assessed the cumulative incidence of AS from middle age, where prevalence is low, up to advanced age. Many studies have reported prevalence rates based on echocardiographic examinations by age 


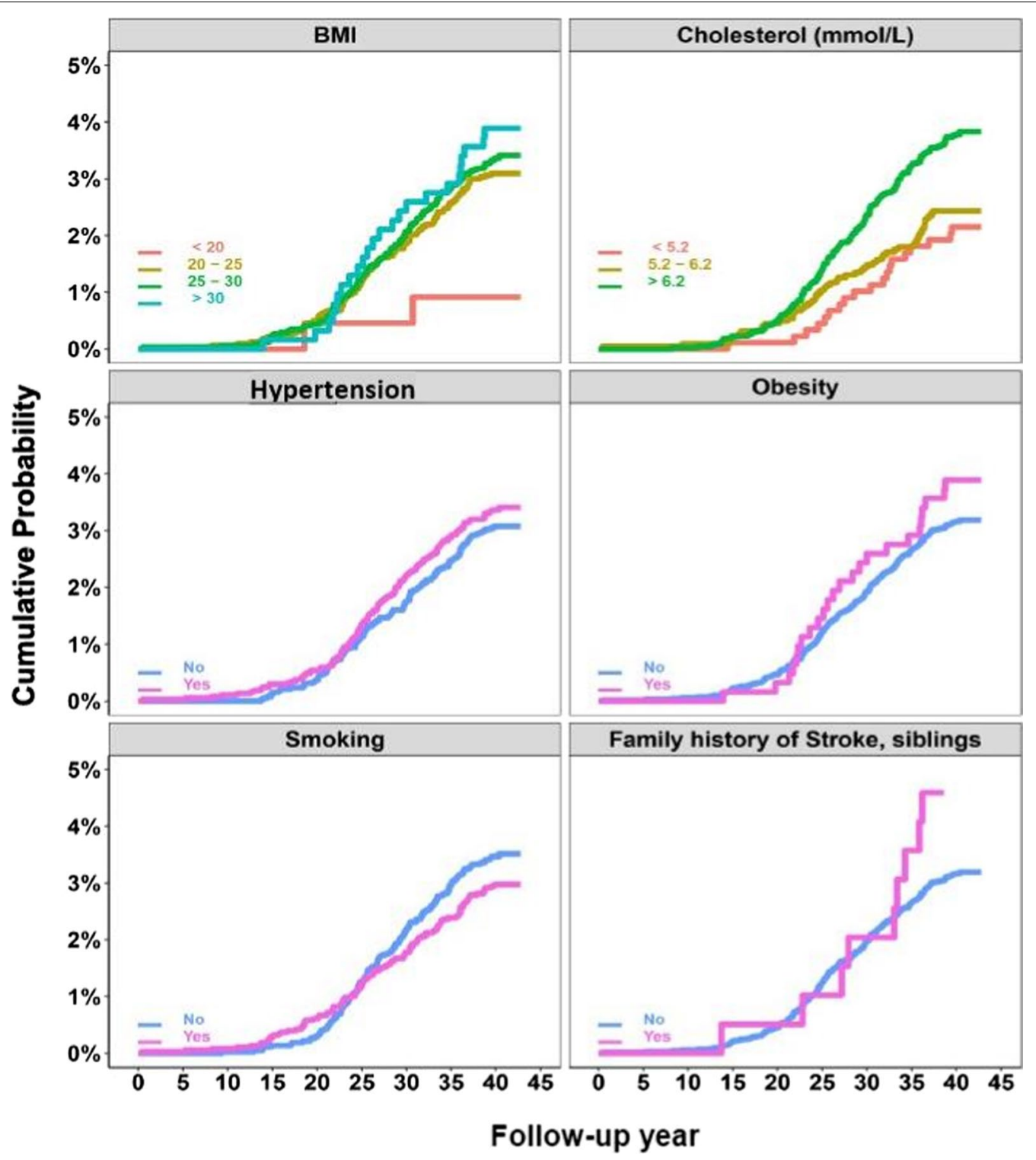

Fig. 2 Cumulative incidence of AS according to categorical baseline factors

group. For instance, rising rates from $1.3 \%$ between 60 and 69 and 3.9\% between 70 and 79 years have been reported in the Tromsø study [1]. Another study based on three cohorts of randomly selected US adults from the general population reported an increase from $0.7 \%$ in $18-44$-year-olds to $13.3 \%$ in the age group $\geq 75$ [21]. In addition, the estimated prevalence may vary greatly depending on the criteria used $[7,22]$. In this study we investigated a population diagnosed with AS in the hospital using registered diagnostic codes. In contrast, most of the prevalence studies used echocardiographic-verified AS in the general population. Our results are therefore not directly comparable. Some studies have shown that male sex could be a risk factor for AS [7, 21, 23]. Thus, the cumulative incidence of our cohort containing only men may be overestimated.

The second goal of this study was to identify factors at baseline or during follow-up that could predict individuals with an elevated risk of developing AS during their lifetime. The extended follow-up of our study participants (42.8 years) poses problems in studying a slowly progressive disease such as AS, with death as a competing event. To address this issue we studied the cohort in three overlapping time intervals. In the first interval, the individuals still alive after 25 years and free of AS were followed until the end. Similar follow-up was conducted 


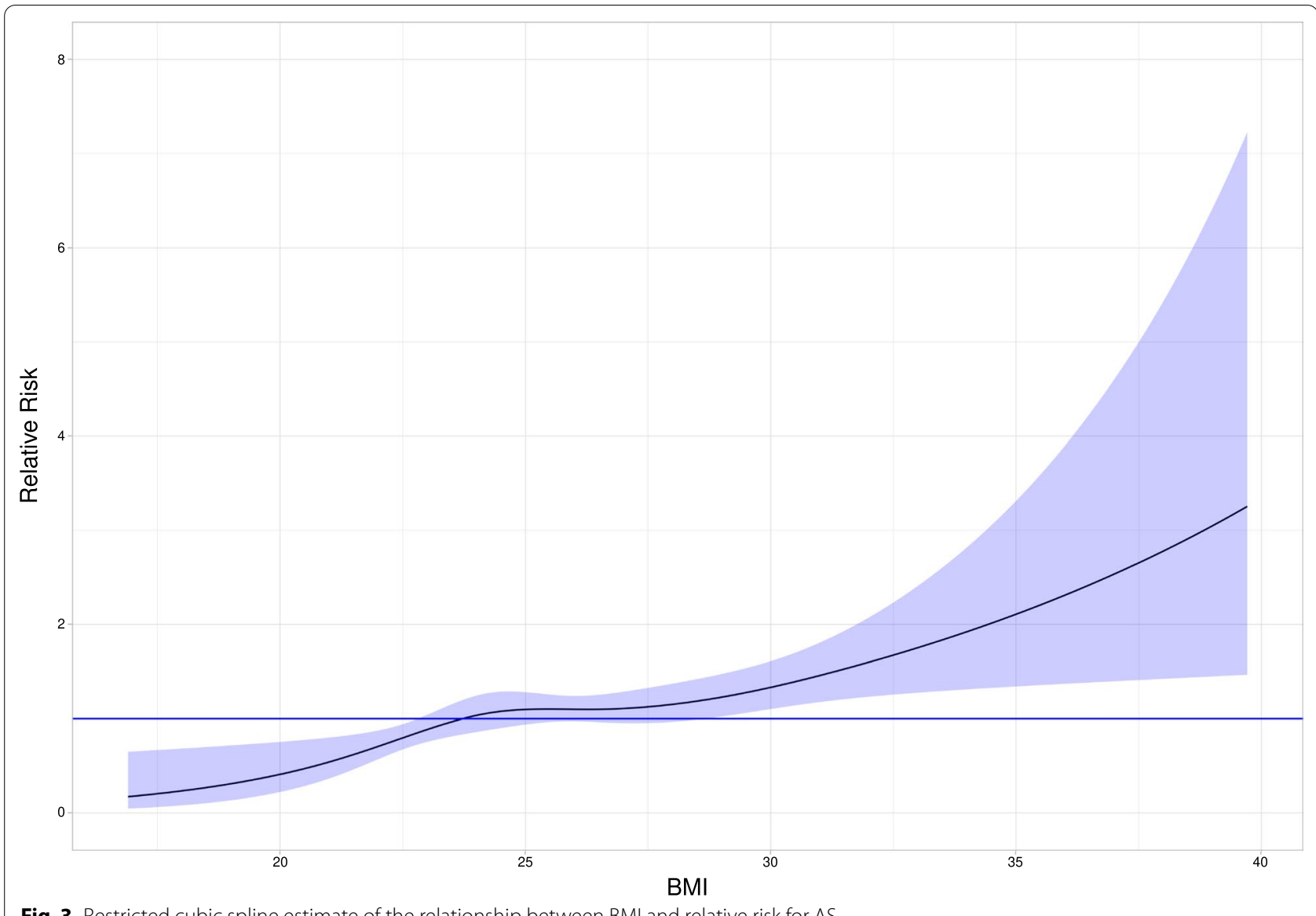

Fig. 3 Restricted cubic spline estimate of the relationship between BMI and relative risk for AS

Table 3 Hazard ratios risk for AS for the whole cohort relative to the BMI with reference category of 20.0-22.5 adjusted for (1) age (model 1), (2) age, baseline smoking, sedentary activity and family history of stroke or myocardial infarction

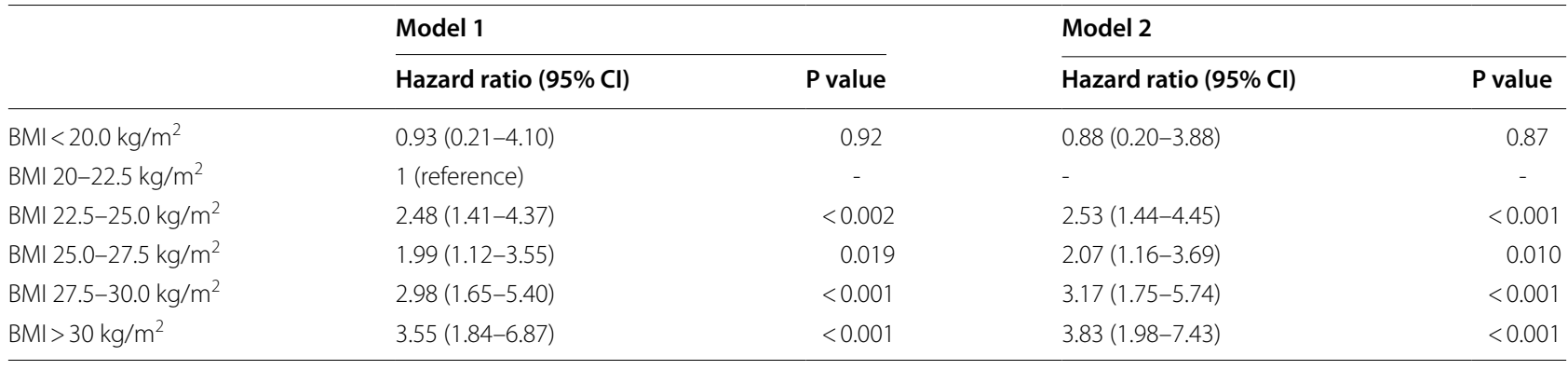

$B M I$ body mass index

for the intervals 30 and 35 years after the baseline as start point. In this manner, we wanted to determine whether the baseline factors or the time-updated comorbidities associated with the incidence of AS in the whole followup interval were still important with increasing longevity, retaining the predictive power or even increasing in effect (e.g. the variables "obesity" and "smoking"), due to association of these factors with the competing risk of death.

We found that obese individuals at baseline had a $64 \%$ higher risk of receiving a diagnosis of AS in the whole cohort. This risk increased to $83 \%$ in the first group and was three times higher in the longest surviving participants, but not in the intermediate group, although 
estimates were numerically similar. The spline function suggested a curvilinear association between BMI and AS; however, because few men were obese at baseline, the effect of severe obesity could not be investigated in our sample. Yet, our results provide some data and help clarify this issue, which has been controversial. Some studies showed a positive association between AS and obesity, including a Swedish study using patient registries [24], a large case-control study with older patients with severe calcified AS [4], and a recent Danish study [5]. Three more studies showed a positive correlation between BMI and aortic valve calcification $[8,25,26]$, whereas three others did not show such a correlation. A substudy of SEAS (Simvastatin Ezetimibe in AS) failed to find an association between AS and obesity in multivariable analysis. Still, in this study, all the patients who had CAD, diabetes mellitus, peripheral arterial disease, cerebrovascular disease or other indication for treatment with statins were excluded [15]. No link was found either between weight and aorta valve calcification in a small cross-sectional study [27]. A larger, cross-sectional study of 5,201 patients $\geq 65$ years enrolled in the Cardiovascular Health Study, where aortic sclerosis and AS were considered together also failed to observe an association between weight and aorta valve calcification [7]. However, in this study, $<10 \%$ of those with aortic disease were defined as AS and, in addition, the cross-sectional design does not permit to investigate the effect in time of obesity on AS. Finally, another study, in an elderly, unselected population, lower BMI (leanness) was associated with a higher risk for aortic valve calcification [10]. Accordingly, although aortic non-stenotic disease may progress to stenosis, risk factors for aortic sclerosis or calcification may differ from those associated with AS progression. In clinical studies AS patients with obesity [28] or metabolic syndrome $[29,30]$ had a more accelerated AS progression, suggesting that BMI over the normal limit might play an important role in AS physiopathology.

A possible explanation for the effect of high BMI on the development or progression of AS might be that overweight/obesity is associated with other risk factors of atherosclerosis (such as diabetes, hypercholesterolemia, hypertension) that might lead to the incipient phase of the process of valve degeneration [3]. In addition, the inflammatory state accompanying obesity [31] may play a role in the development of early lesions on the aortic valves, lesions characterized by an active inflammatory process [3].

Hypercholesterolemia is a key factor in the development of atherosclerotic plaque and coronary artery disease. Similarly, lipid accumulation has been shown in early lesions appearing on degenerative aortic valves [3]. Therefore, it is expected that high cholesterol levels would increase the risk of AS development. However, findings on the relationship between hypercholesterolemia and AS development or progression are inconsistent and questionable. In our study, cholesterol level was associated with the risk of being diagnosed with AS in the whole cohort, but not when those surviving $\geq 35$ years were analyzed separately. The higher mortality risk may explain that the association is not significant in this last, most "healthy" group. These individuals (now in their $80 \mathrm{~s})$ with higher cholesterol levels have less chance of surviving and be diagnosed with AS after 35 years of follow-up.

Hypertension is often associated with degenerative AS and portends worse prognosis and faster progression [32]. Our study found that hypertension was associated with being diagnosed with AS, similar to previous associations between hypertension and AS [7, 10, 11] or aortic sclerosis [6,33]. Potential explanations for the association of hypertension with AS include common risk factors and the possibility that hypertension causes abnormally high tensile stress on the aortic leaflet. Nevertheless, age may act as the common factor, as both blood vessels stiffness and AS increase with age. Smoking is thought to be linked to dyslipidaemia and hypertension and as a promoter to atherosclerosis. Thus, the association that we found with the hazard of AS was expected. Although smoking at baseline was less common among those surviving longest, smoking associates with AS development in all the groups with follow-up $\geq 25$ years.

Similarly, having atrial fibrillation during follow-up also associated with a later diagnosis of AS, which could be explained by shared common risk factors between AS and atrial fibrillation. The link between heredity for stroke in siblings and AS could be due to shared genetic and environmental factors leading to atherosclerosis and stroke in these families. Still, it could just as well be a chance finding. We also found an association between renal failure and the risk to develop AS, but only in the group followed 25-43 years. Renal failure seems to be a a risk factor for AS, as showed in the literature [34]. However, the wide confidence intervals in our study preclude firm conclusions as to the size of this effect.

\section{Strengths and limitations}

Strengths of the present study include a large and relatively homogeneous study population, making it possible to eliminate some confounders. In addition, we had an extended follow-up (43 years), which is a strength in this rather slowly evolving disease. Yet, the study has some limitations. First, we used diagnostic codes instead of echocardiography and patients with potentially undiagnosed AS at baseline could have been included in the study. However, given that AS is unusual in men in their 
early $50 \mathrm{~s}$, this is unlikely to have affected our results. The use of echocardiography in Gothenburg for the diagnosis of valve disease began in 1970, in addition to phonocardiography, pulse curves and heart catheterization used at this time, methods with low sensitivity that could have missed AS diagnosis. Even so, it is unlikely that surviving men with AS would not have been diagnosed at some point, given the characteristic heart murmur associated with AS. Second, because the information provided in a registry is limited, we could not describe the etiology or degree of severity of aortic valve morphology. We had no access to echocardiographic examinations and patient records could not be retrieved to a sufficient extent to validate diagnoses. Third, we could identify the outcome (i.e. AS) only in hospital patients because the NPR does not contain information about patients managed only in primary care. Fourth, we only studied middle-aged men and therefore our results cannot be generalized to women or older men.

\section{Conclusion}

Our study showed that the cumulative incidence of AS was $3.2 \%$ in men followed from the age of 47-55 years and up to 43 years. Obesity, cholesterol level, hypertension, being a smoker or being diagnosed with atrial fibrillation during follow-up were associated with increased risk of developing AS. Considering that increasing longevity of the population leads to rising AS prevalence and that many of these factors are modifiable, a strategy delaying progression of aortic sclerosis and preventing significant AS might reduce the need for invasive aortic valvular intervention. Accordingly, multiple approaches targeting all known risk factors could reduce AS or delay its progression.

\begin{abstract}
Abbreviations
AS: Aortic stenosis; BMI: Body mass index; BP: Blood pressure; Cl: Confidence interval; DBP: Diastolic blood pressure; ICD: International Classification of Disease; IQR: Interquartile range; HR: Hazard ratio; NPR: Swedish National Patient Registry; PP: Pulse pressure; PPS: Primary Prevention Study; SBP: Systolic blood pressure; SEAS: Simvastatin Ezetimibe in AS.
\end{abstract}

\section{Acknowledgements}

Not applicable.

\begin{abstract}
Authors' contributions
SK, participated in analysis (partially) and interpretation of data, in reviewing the literature and in drafting the manuscript. ET participated in revising the manuscript. GL analysed the data. AR and MF designed the study, permitted the access to the database containing the participants. In addition, participated to the data interpretation and critically revised the manuscript. All the authors gave final approval and agree to be accountable for all aspects of work ensuring integrity and accuracy. All authors read and approved the final manuscript.
\end{abstract}

\section{Funding}

Open access funding provided by University of Gothenburg. This work was supported by the Swedish agreement between the government and the county councils concerning economic support for providing an infrastructure for research and education of doctors, and the Swedish Research Council (ALF 73400, ALFGBG-717211), the Regional Development Fund, Västra Götaland County, Sweden (FOU-VGR), the Swedish Heart and Lung Foundation [20180366], the Swedish Research Council [2018-02527, VRREG 2019-00193] and by the Gothenburg Society of Medicine (20/935037). The funding bodies did not influence any phase of the study, from design to submission.

\section{Availability of data and materials}

Data are available from the sources stated in the paper on request to the data providers, fulfilling legal and regulatory requirements and with the permission from the Swedish Ethical Review Authority. Supporting data may be accessed if requested by contact with the authors.

\section{Declarations}

\section{Ethics approval and consent to participate}

In this study, initiated over 50 years ago, participant consent was considered implicit on attending the screening investigation, written consent was not a requirement from the ethics committee, and the subsequent interventions were carried out as part of clinical management of high risk individuals. The men in the control group were never contacted, only followed through local and national registries [35]. However, the process of running the data file of the participants against the Swedish National Patient Registry and the Swedish Cause of Death Registry was approved by the Ethical Committee at the University of Gothenburg (886-13, T187-16). The study complied with the Declaration of Helsinki issued 1974

\section{Consent for publication}

All the authors read and approved the final version of the manuscript, and approved the submitted manuscript and the submission for potential publication.

\section{Competing interests}

The authors have no competing interests to declare that are relevant to the content of this article.

\section{Author details}

${ }^{1}$ Department of Molecular and Clinical Medicine, Institute of Medicine, Sahlgrenska Academy, University of Gothenburg, Gothenburg, Sweden. ${ }^{2}$ Region Västra Götaland, Sahlgrenska University Hospital/Östra Hospital, Diagnosvägen 11, 41650 Gothenburg, Sweden.

Received: 8 September 2021 Accepted: 2 February 2022

Published online: 13 February 2022

\section{References}

1. Eveborn GW, Schirmer H, Heggelund G, Lunde P, Rasmussen K. The evolving epidemiology of valvular aortic stenosis. The Tromso study. Heart. 2013;99(6):396-400.

2. Horstkotte D, Loogen F. The natural history of aortic valve stenosis. Eur Heart J. 1988;9:57-64.

3. Otto CM, Kuusisto J, Reichenbach DD, Gown AM, O'Brien KD. Characterization of the early lesion of "degenerative" valvular aortic stenosis. Histol Immunohistochem Stud Circ. 1994:90(2):844-53.

4. Peltier M, Trojette F, Sarano ME, Grigioni F, Slama MA, Tribouilloy CM. Relation between cardiovascular risk factors and nonrheumatic severe calcific aortic stenosis among patients with a three-cuspid aortic valve. Am J Cardiol. 2003;91 (1):97-9.

5. Kaltoft M, Langsted A, Nordestgaard BG. Obesity as a causal risk factor for aortic valve stenosis. J Am Coll Cardiol. 2020;75(2):163-76.

6. Yan AT, Koh M, Chan KK, Guo H, Alter DA, Austin PC, et al. Association between cardiovascular risk factors and aortic stenosis: the CANHEART aortic stenosis study. J Am Coll Cardiol. 2017;69(12):1523-32.

7. Stewart BF, Siscovick D, Lind BK, Gardin JM, Gottdiener JS, Smith VE, et al. Clinical factors associated with calcific aortic valve disease. Cardiovascular Health Study. J Am Coll Cardiol. 1997;29(3):630-4. 
8. Messika-Zeitoun D, Bielak LF, Peyser PA, Sheedy PF, Turner ST, Nkomo $V T$, et al. Aortic valve calcification: determinants and progression in the population. Arterioscler Thromb Vasc Biol. 2007;27(3):642-8.

9. Deutscher S, Rockette HE, Krishnaswami V. Diabetes and hypercholesterolemia among patients with calcific aortic stenosis. J Chronic Dis. 1984;37(5):407-15.

10. Lindroos M, Kupari M, Valvanne J, Strandberg T, Heikkila J, Tilvis R. Factors associated with calcific aortic valve degeneration in the elderly. Eur Heart J. 1994:15(7):865-70.

11. Ljungberg J, Johansson B, Engström KG, Norberg M, Bergdahl IA, Söderberg S. Arterial hypertension and diastolic blood pressure associate with aortic stenosis. Scand Cardiovasc J. 2019;53(2):91-7.

12. Kontogeorgos S, Thunström E, Basic C, Hansson PO, Zhong Y, Ergatoudes $\mathrm{C}$, et al. Prevalence and risk factors of aortic stenosis and aortic sclerosis: a 21-year follow-up of middle-aged men. Scand Cardiovasc J. 2020:54(2):115-23.

13. Obesity: preventing and managing the global epidemic. Report of a WHO consultation. World Health Organization technical report series. 2000;894:i-xii, 1-253.

14. Poirier P, Giles TD, Bray GA, Hong Y, Stern JS, Pi-Sunyer FX, et al. Obesity and cardiovascular disease: pathophysiology, evaluation, and effect of weight loss. Arterioscler Thromb Vasc Biol. 2006;26(5):968-76.

15. Rogge BP, Cramariuc D, Lonnebakken MT, Gohlke-Barwolf C, Chambers JB, Boman K, et al. Effect of overweight and obesity on cardiovascular events in asymptomatic aortic stenosis: a SEAS substudy (Simvastatin Ezetimibe in Aortic Stenosis). J Am Coll Cardiol. 2013;62(18):1683-90.

16. Wilson PW, D'Agostino RB, Sullivan L, Parise H, Kannel WB. Overweight and obesity as determinants of cardiovascular risk: the Framingham experience. Arch Intern Med. 2002;162(16):1867-72.

17. Rabkin SW, Mathewson FA, Hsu PH. Relation of body weight to development of ischemic heart disease in a cohort of young North American men after a 26 year observation period: the Manitoba Study. Am J Cardiol. 1977;39(3):452-8.

18. Bjorck L, Novak M, Schaufelberger M, Giang KW, Rosengren A. Body weight in midlife and long-term risk of developing heart failure-a 35-year follow-up of the primary prevention study in Gothenburg, Sweden. BMC Cardiovasc Disord. 2015;15:19.

19. Wilhelmsen L, Berglund G, Elmfeldt D, Tibblin G, Wedel H, Pennert K, et al. The multifactor primary prevention trial in Goteborg, Sweden. Eur Heart J. 1986;7(4):279-88.

20. R Core Team. R: a language and environment for statistical computing. $R$ Foundation for Statistical Computing: 2019.

21. Nkomo VT, Gardin JM, Skelton TN, Gottdiener JS, Scott CG, EnriquezSarano M. Burden of valvular heart diseases: a population-based study. Lancet. 2006;368(9540):1005-11.

22. Lindroos M, Kupari M, Heikkila J, Tilvis R. Prevalence of aortic valve abnormalities in the elderly: an echocardiographic study of a random population sample. J Am Coll Cardiol. 1993;21(5):1220-5.

23. Novaro GM, Katz R, Aviles RJ, Gottdiener JS, Cushman M, Psaty BM, et al. Clinical factors, but not $C$-reactive protein, predict progression of calcific aortic-valve disease: the Cardiovascular Health Study. J Am Coll Cardiol. 2007;50(20):1992-8.

24. Larsson SC, Wolk A, Hakansson N, Back M. Overall and abdominal obesity and incident aortic valve stenosis: two prospective cohort studies. Eur Heart J. 2017:38(28):2192-7.

25. Owens DS, Katz R, Takasu J, Kronmal R, Budoff MJ, O'Brien KD. Incidence and progression of aortic valve calcium in the Multi-ethnic Study of Atherosclerosis (MESA). Am J Cardiol. 2010;105(5):701-8.

26. Thanassoulis G, Massaro JM, Cury R, Manders E, Benjamin EJ, Vasan RS, et al. Associations of long-term and early adult atherosclerosis risk factors with aortic and mitral valve calcium. J Am Coll Cardiol. 2010;55(22):2491-8.

27. Aksoy Y, Yagmur C, Tekin GO, Yagmur J, Topal E, Kekilli E, et al. Aortic valve calcification: association with bone mineral density and cardiovascular risk factors. Coron Artery Dis. 2005;16(6):379-83.

28. Ngo MV, Gottdiener JS, Fletcher RD, Fernicola DJ, Gersh BJ. Smoking and obesity are associated with the progression of aortic stenosis. Am J Geriatr Cardiol. 2001;10(2):86-90.

29. Briand M, Lemieux I, Dumesnil JG, Mathieu P, Cartier A, Després J-P, et al. Metabolic syndrome negatively influences disease progression and prognosis in aortic stenosis. J Am Coll Cardiol. 2006;47(11):2229-36.
30. Capoulade R, Clavel M-A, Dumesnil JG, Chan KL, Teo KK, Tam JW, et al. Impact of metabolic syndrome on progression of aortic stenosis: influence of age and statin therapy. J Am Coll Cardiol. 2012;60(3):216-23.

31. Gregor MF, Hotamisligil GS. Inflammatory mechanisms in obesity. Annu Rev Immunol. 2011:29:415-45.

32. Capoulade R, Clavel MA, Mathieu P, Côté N, Dumesnil JG, Arsenault M, et al. Impact of hypertension and renin-angiotensin system inhibitors in aortic stenosis. Eur J Clin Investig. 2013;43(12):1262-72.

33. Iwata S, Russo C, Jin Z, Schwartz JE, Homma S, Elkind MS, et al. Higher ambulatory blood pressure is associated with aortic valve calcification in the elderly: a population-based study. Hypertension (Dallas, Tex: 1979). 2013;61(1):55-60.

34. Vavilis G, Bäck M, Occhino G, Trevisan M, Bellocco R, Evans M, et al. Kidney Dysfunction and the Risk of Developing Aortic Stenosis. J Am Coll Cardiol. 2019;73(3):305-14.

35. Wilhelmsen L, Tibblin G, Werkö L. A primary preventive study of Gothenburg. Sweden Prev Med. 1972;1(1):153-60.

\section{Publisher's Note}

Springer Nature remains neutral with regard to jurisdictional claims in published maps and institutional affiliations.
Ready to submit your research? Choose BMC and benefit from:

- fast, convenient online submission

- thorough peer review by experienced researchers in your field

- rapid publication on acceptance

- support for research data, including large and complex data types

- gold Open Access which fosters wider collaboration and increased citations

- maximum visibility for your research: over 100M website views per year

At BMC, research is always in progress.

Learn more biomedcentral.com/submissions 